\title{
Morphological Variation of Sordellina punctata (Peters, 1880) with Notes on the Phylogenetic Position of the Genus within the Family Dipsadidae (Serpentes)
}

\author{
Bruno Henrique V. Miranda ${ }^{1}$ and Daniel Silva Fernandes ${ }^{1,2}$ \\ ${ }^{1}$ Departamento de Zoologia, Instituto de Biologia, Universidade Federal do Rio de Janeiro, Ilha do Governador, \\ 21941-902 Rio de Janeiro, RJ, Brazil \\ ${ }^{2}$ Departamento de Vertebrados, Museu Nacional, Universidade Federal do Rio de Janeiro, Quinta da Boa Vista, \\ 20940-040 Rio de Janeiro, RJ, Brazil
}

Correspondence should be addressed to Bruno Henrique V. Miranda, brunohvmiranda@gmail.com

Received 30 March 2012; Revised 23 June 2012; Accepted 7 July 2012

Academic Editor: Hynek Burda

Copyright ( 2012 B. H. V. Miranda and D. S. Fernandes. This is an open access article distributed under the Creative Commons Attribution License, which permits unrestricted use, distribution, and reproduction in any medium, provided the original work is properly cited.

\begin{abstract}
Sordellina punctata (Peters, 1880) is a poorly known species from Brazil that, until recently, had an uncertain phylogenetic position. Sixty-one specimens of Sordellina punctata were examined, representing different localities encompassing the known geographic distribution of this taxon. Eight skulls and five hemipenes were prepared and described in detail and data on scale variation and color pattern as well as morphometric data were analyzed. The skull bones described, as well as the hemipenis of $S$. punctata, were compared to available data in the literature referred to members of the tribe Echinanterini and related taxa. Sordellina punctata presents an average snout-vent length of $31.5 \mathrm{~cm}$ for males and 40.2 for females and has an average of 149 ventral scales in males and 157 in females. The data presented here reinforce the necessity of a greater amount of osteological descriptive studies, especially of members of the tribe Echinanterini, in order to evaluate the recently proposed hypothesis of relationship of $S$. punctata and these taxa.
\end{abstract}

\section{Introduction}

The monotypic species Sordellina punctata (Peters, 1880) is rare in scientific collections and difficult to find in nature. It inhabits the Atlantic Forest wetlands from Brazil, has aglyphous dentition, and feeds on small and soft invertebrates [1], but has a record of stomach contents with Chthonerpeton indistinctum (Gymnophiona, Typhlonectidae) [2]. Available data in the literature about this species is also scarce. Its taxonomic history was reported by Hoge [3], Peters and Orejas-Miranda [4], and Hoge and Romano [5], the hemipenis was described by Zaher [6], and the systematic position of the genus was considered by Zaher et al. [7] and Vidal et al. [8] as Dipsadidae incertae sedis, group already referred by some authors as Colubridae [9]. Recently, Grazziotin et al. [9] provided the first phylogenetic analysis with $S$. punctata as a terminal taxon. The results show $S$. punctata nested within the tribe Echinanterini, as the sister group of the genus Taeniophallus Cope 1895. This paper aims to provide for the first time a detailed description of the skull of this taxon as well as complementary data on morphometric variation, hemipenis morphology, and geographic distribution. The characteristics of the skull and/or hemipenis presented by $S$. punctata were compared with data available in the literature of some members of Echinanterini as well as representatives of related tribes (e.g., Hydropsini, Pseudoboini, Tachymenini) according to Grazziotin et al. [9].

\section{Materials and Methods}

Specimens examined are housed in the herpetological collection of Instituto Butantan (IBSP), São Paulo, Brazil. Sixty-one (61) specimens were recorded and analyzed: 17 males and 44 females. The following characters of external morphology were analyzed: number of ventrals; number of 


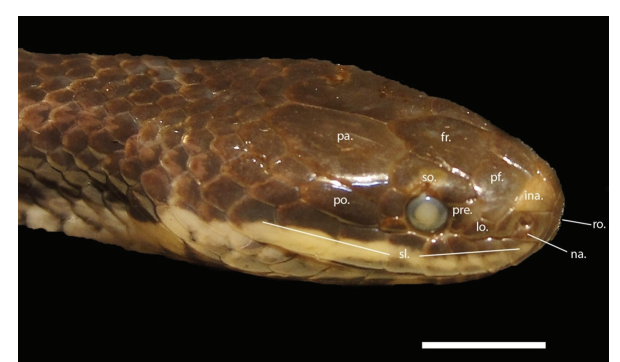

FIgURE 1: Dorsolateral view of the head of Sordellina punctata (IBSP 66199). Bar $=5 \mathrm{~mm}$. fr: frontal; ina: internasal; lo: loreal; na: nasal; pa: parietal; po: postorbital; pf: prefrontal; pre: preocular; ro: rostral; sl: supralabials; so: supraocular.

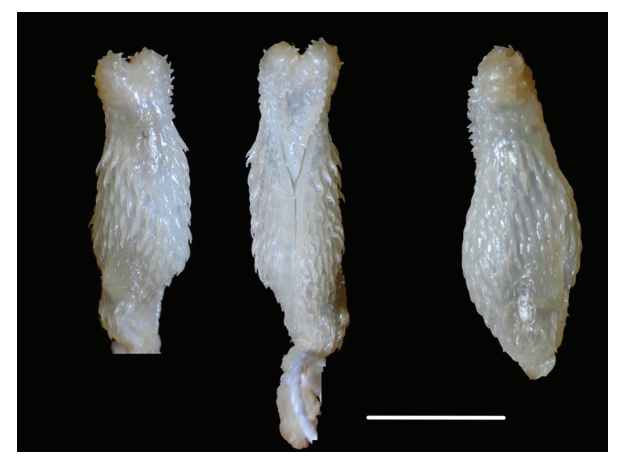

(a)

(b)

(c)

Figure 2: Hemipenis of Sordellina punctata (IBSP 71106). (a) asulcate side; (b) sulcate side; (c) lateral view. Bar $=5 \mathrm{~mm}$.

subcaudals; number of supralabials; number of infralabials; number of gulars; number of temporals; number of postorbitals; condition of the cloacal plate; condition of nasal scale; presence or absence of the loreal scale; number of dorsals; number of supralabials in contact with the orbit; number of infralabials in contact with 1st and 2nd pairs of genial scales; presence or absence of keeled scales; presence or absence of apical pits. The color pattern of Sordellina punctata in preservative was also described. The terminology adopted for the cephalic shields of S. punctata follows Peters [10] and the ventral scales counting follows Dowling [11].

External measurements for the length of the head, interocular length, and between the quadrate bones and internal measurements for the length and width of the cranium and dentary length were obtained with a digital caliper to the nearest $0.1 \mathrm{~mm}$. The skull length was measured from the anteriormost medial margin of the premaxilla to the medial portion of the occipital condyle and the skull width was measured at the level of the postorbital bones. Snout-vent length (SVL) and tail length (TL) were taken with a ruler to the nearest millimeter. The presence of sexual dimorphism was determined with a Student's $t$-test using the number of ventral and subcaudal scales. The assumptions of homoscedasticity and normality were verified through the Levene and Kolmogorov-Smirnov tests, respectively [12]. Hemipenis from five males were prepared according to the technique proposed by Pesantes [13]. Terminology for

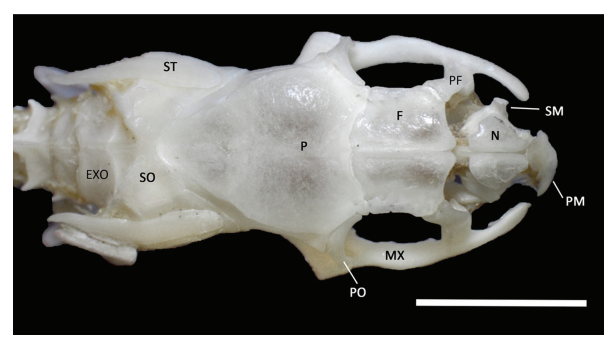

FIgURE 3: Dorsal view of the skull of Sordellina punctata (IBSP 22313). Bar $=5 \mathrm{~mm}$. Exo: exoccipital; f: frontal; $\mathrm{mx}$ : maxilla; $\mathrm{n}$ : nasal; p: parietal; pf: prefrontal; pm: premaxilla; po: postorbital; sm: septomaxilla; so: supraoccipital; st: supratemporal.

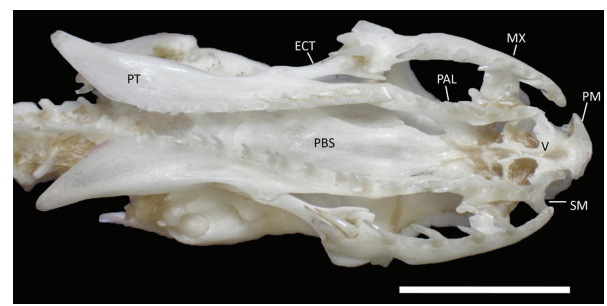

FIGURE 4: Ventral view of the skull of Sordellina punctata (IBSP 22313). Bar $=5 \mathrm{~mm}$. Abbreviations other than in previous figures are ect: ectopterygoid; pal: palatine; pbs: parabasisphenoid; pt: pterygoid; v: vomer.

hemipenis description follows Dowling and Savage [14] and Zaher [6]. Skulls from eight adult specimens (4 males and 4 females) were prepared according to the technique proposed by Hangay and Dingley [15]. Four articulated and four disarticulated skulls were analyzed with special consideration of bone suturing. Osteological nomenclature follows Underwood [16] and mostly Cundall and Irish [17]. The skull was divided into four regions according to Cundall and Irish [17]: snout, braincase, palatomaxillary complex, and suspensorium-mandible.

\section{Morphological Variation}

3.1. Diagnosis (Figures 1, 2, 3, and 4). Sordellina punctata differs from other dipsadidae species by the following combination of characters: presence of one preocular and two postoculars; temporal $1+2$, with the anterior one in contact with both postoculars; usually eight supralabials; seven to nine infralabials; dorsals 17-17-17; smooth scales; no apical tips; ventrals 137-174 in females and 135-161 in males; subcaudals 36-56 in females and 40-57 in males; cloacal plate divided; dark-brown head in dorsal view with white spots in supralabials, sometimes fused and forming a line; hemipenis slightly bilobed; lobular region covered by papillae; sulcus spermaticus divided just below the lobular region; 11 to 14 prediastemal maxillary teeth and two postdiastemal teeth; parietal crests with no contact at the rear end of the bone.

3.2. Variation. Sordellina punctata showed sexual dimorphism relative to the number of ventrals $(t=2.711 ; P<0.01$; $n=60$ ), females with higher values, and subcaudal scales 
TABle 1: Meristic and morphometric variation of Sordellina punctata. Data expressed by mean \pm standard deviation (amplitude).

\begin{tabular}{lccc}
\hline Meristic and morphometric data & Total $(n=61)$ & Males $(n=17)$ & Females $(n=44)$ \\
\hline Ventrals & $154.97 \pm 11.28(135-174)$ & $149 \pm 9.71(135-161)$ & $157.33 \pm 11.26(137-174)$ \\
Subcaudals & $45.51 \pm 5.98(36-57)$ & $49.76 \pm 4.52(40-57)$ & $43.70 \pm 5.63(36-56)$ \\
Supralabials & $8.03 \pm 0.18(7-9)$ & & \\
Infralabials & $8.10 \pm 0.44(7-9)$ & & \\
Gulars & $4.93 \pm 0.40(4-6)$ & & $14.56 \pm 2.29(8.9-18.24)$ \\
Head length (mm) & $13.82 \pm 2.49(8.9-18.24)$ & $70.9 \pm 22.7(90.7-109)$ & $77.2 \pm 20.1(30-115)$ \\
Tail length (mm) & $75.3 \pm 20.9(30-115)$ & $315.7 \pm 97.6(170-526)$ & $401.6 \pm 91.0(157-599)$ \\
Snout-vent length $(\mathrm{mm})$ & $376.9 \pm 100.1(157-599)$ & $4.26 \pm 0.90(2.75-6.78)$ & $4.74 \pm 0.76(2.66-5.93)$ \\
Interocular width (mm) & $4.59 \pm 0.83(2.66-6.78)$ & $6.03 \pm 1.14(4.51-9.42)$ & $7.12 \pm 1.29(3.64-9.63)$ \\
Width of head-quadrate $(\mathrm{mm})$ & $6.80 \pm 1.34(3.64-9.63)$ & &
\end{tabular}

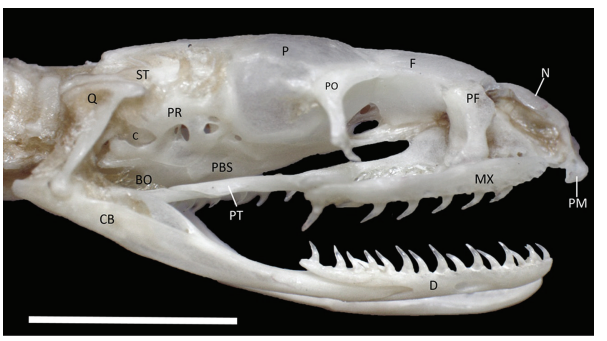

FIGURE 5: Lateral view of the skull of Sordellina punctata (IBSP 62809). Bar $=5 \mathrm{~mm}$. Abbreviations other than in previous figures are cb: compound bone; c: columella auris; d: dentary; pr: prootic.

$(t=3.929 ; P<0.01 ; n=57)$, males with higher values. Sordellina punctata also presented a medium-size body, with SVL reaching up to $600 \mathrm{~mm}$ and tail length reaching up to $115 \mathrm{~mm}$. The size of the head reached a maximum length of $18.24 \mathrm{~mm}$, with the maximum width between the eyes of $6.78 \mathrm{~mm}$ and a maximum width of $9.63 \mathrm{~mm}$ in the level of quadrate bones. The complete data regarding meristic and morphometric characters are showed in Table 1.

3.3. Color Pattern in Preservative. Sordellina punctata presented a color pattern with dark-brown head on dorsal view, dark-brown supralabials with white spots forming a line over the supralabial scales and dark-brown gular scales with white spots. Twenty-seven specimens showed a little white dot above each parietal scale, typically observed in all juveniles and less evident in adult specimens, indicating a possible ontogenetic or intraspecific variation. The dorsal darkbrown scales have white spots on the 2nd and 3rd rows, sometimes forming a line on the anterior portion of the body achieving up to the 31 th ventral scale. Ventral dark-brown scales with two series of white spots along the body. These two series of white spots may be fused, giving the appearance that ventral scales are white with dark-brown lateral edges.

3.4. Hemipenis Description (Figure 2). Organ slightly bilobed, semicapitate, with bifurcation of the lobes occurring only at the apical portion. Lobular region covered by papillae. On the intrasulcular and lateral regions, papillae are densely distributed on a series of irregular rows. On the asulcate side, papillae more sparsely distributed. Sulcus spermaticus divides just below the papillate region (capitulum), approximately on the distal third of hemipenial body. Branches have centrolineal orientation, terminating on distal region of the lobes. Hemipenial body covered with spines. In lateral view, spines arranged in six to seven rows, being larger in the upper rows and decreasing near the basal portion of the organ. The same pattern of spine size is observed on both sulcate and asulcate side. Basal portion of hemipenial body shows a twisting, with sulcus spermaticus located in a lateral position at this region, moving to a central position on the proximal third of the hemipenial body. The basal region of hemipenis bears only a few and small spinules over this area.

\section{Skull Description}

The skull of S. punctata (Figures 3, 4, and 5) has a pentagonal and elongated aspect, being slightly constricted in the median portion. In dorsal view, the maxillae curve anteriorly towards midline. Dorsal surface is flat, with a slight descending slope in the occipital region. In lateral view, the height of the skull shows a slight increase in the anteroposterior direction, from the level of the orbit, between the frontal and parietal bones. The premaxilla, along with the maxilla, forms an arch on the anterior part of the skull.

Braincase was about two-times longer than wide, ranging from $11.68 \mathrm{~mm}$ to $14.26 \mathrm{~mm}$ long and $5.17 \mathrm{~mm}$ to $6.88 \mathrm{~mm}$ wide (Table 2). Mandible varied from $5.24 \mathrm{~mm}$ to $7.74 \mathrm{~mm}$ long (Table 2). Next section shows the description of individual bones according to the basic organization of snake skull proposed by Cundall and Irish [17].

\subsection{Snout}

4.1.1. Premaxilla (Figures 3, 4, 5, 6, and 7). Premaxilla is small, slightly triangular in frontal view, toothless, and positioned on the anterior edge of the skull. The ventral edge is curved and concave. The premaxilla shows an ascending or dorsal process contacting the anterior edge of nasals, just a laminar contact with no overlapping, and two transverse processes, also called maxillary processes of premaxilla. The maxillary processes are separated from maxilla by cartilage 
TABle 2: Meristic and morphometric variation of the skull of Sordellina punctata. Data expressed by mean \pm standard deviation (amplitude).

\begin{tabular}{lccc}
\hline Skull data & Total $(n=8)$ & Male $(n=4)$ & Female $(n=4)$ \\
\hline Skull length $(\mathrm{mm})$ & $12.73 \pm 1.02(11.68-14.26)$ & $12.71 \pm 1.20(11.68-13.07)$ & $12.76 \pm 1.00(11.86-14.26)$ \\
Skull width $(\mathrm{mm})$ & $6.12 \pm 0.61(5.17-6.88)$ & $6.34 \pm 0.38(5.17-6.37)$ & $5.9 \pm 0.76(5.32-6.88)$ \\
Dentary length $(\mathrm{mm})$ & $6.62 \pm 0.75(5.24-7.74)$ & $6.13 \pm 0.46(5.24-6.61)$ & $7.12 \pm 0.66(5.83-7.59)$ \\
Dentary teeth & $16.56 \pm 1.26(14-18)$ & $17.12 \pm 0.99(15-18)$ & $16 \pm 1.30(14-18)$ \\
Palatine teeth & $10 \pm 0.75(8-11)$ & $10.42 \pm 0.53(10-11)$ & $9.62 \pm 0.74(8-10)$ \\
Pterygoid teeth & $19.25 \pm 1.69(16-24)$ & $19.87 \pm 1.80(18-24)$ & $18.62 \pm 1.40(16-20)$ \\
Maxillary teeth & $12.5 \pm 0.85(11-14)(n=44)$ & $12.73 \pm 0.96(13-16)(n=15)$ & $12.34 \pm 0.76(13-16)(n=29)$ \\
\hline
\end{tabular}

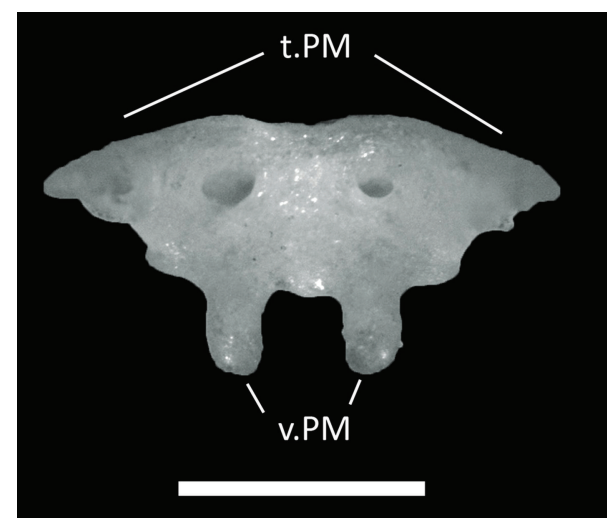

Figure 6: Ventral view of the premaxilla of Sordellina punctata (IBSP 41071). Bar $=1 \mathrm{~mm}$. Abbreviations other than in previous figures are t.PM: transverse process of premaxilla; v.PM: vomerine process of premaxilla.

and muscular tissue. Ventrally, from the medial portion of the bone, two short vomerine processes are present.

4.1.2. Septomaxilla (Figures 3, 4, 5, and 7). Septomaxilla is a paired bone, dorsal to vomers; a prominent dorsolateral process is present laterally. Medial portion of septomaxilla contacts vertical laminae of the nasals and ascending process of premaxilla. On the level of dorsolateral process, in the anteroposterior direction, septomaxilla extends dorsally forming a globular structure with the vomer. From the dorsolateral process, septomaxilla shows a medial narrowing, always contacting the vomer up to the level of the posterior process of the vertical laminae of the nasals.

4.1.3. Nasal (Figures 3 and 5). Nasal is a paired bone situated at the anteromedial portion of the longitudinal axis of the skull, between the premaxilla and frontal bones, covering the nasal cavity dorsally. The anterior edge tapers anteriorly, contacting the premaxilla. The lateral edge expands followed by a constriction at the posterior portion, forming a triangular structure in each half of the nasals, with an apex opposed to the region of contact between nasals, pointing to maxilla. The internasal suture is extensive. The vertical laminae of nasals form the inner wall of nasal cavity and contact the septomaxilla ventrally, along all the extension of the nasal septum. Posterodorsally, nasals do not contact frontal bones.

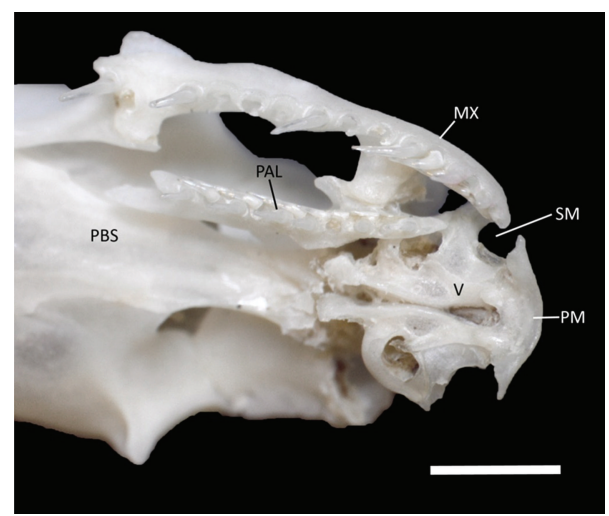

FIgURE 7: Ventral view of the snout of Sordellina punctata (IBSP 49404). Bar $=2 \mathrm{~mm}$.

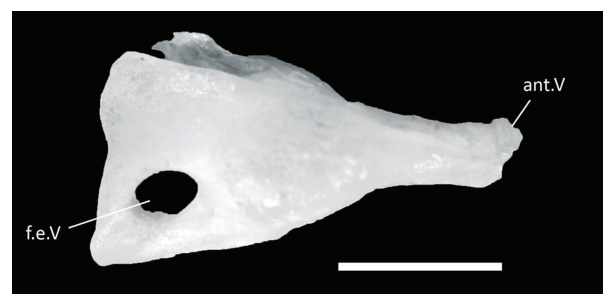

FIGURE 8: Medial view of the vomer of Sordellina punctata (IBSP 41071). Bar $=1 \mathrm{~mm}$. Abbreviations other than in previous figures: ant.V: anterior process of vomer; f.e.V: exochoanal fenestra of vomer.

4.1.4. Vomer (Figures 4, 7, and 8). Vomer is a paired bone positioned anteroventrally in the midline of the skull. Dorsally, the vomer contacts the septomaxilla delimiting the anterior edge of olfactory capsule, which houses the vomeronasal organ. The posteromedial portion is triangular due to the presence of a dorsal and a ventral posterior process forming the base of the triangle. The exochoanal fenestra is situated on the ventral posterior process. The medial surface, through which the partial contact between the vomers occurs, is not straight due to a convexity on the vomeronasal organ region, forming an irregular contact between the vomers. Anteroventrally, the vomer contacts the vomerine process of the premaxilla. The medioventral region has a projection and a lateral enlargement from the medial line of contact between vomers that, along with the septomaxilla, gives this region a globular aspect. 


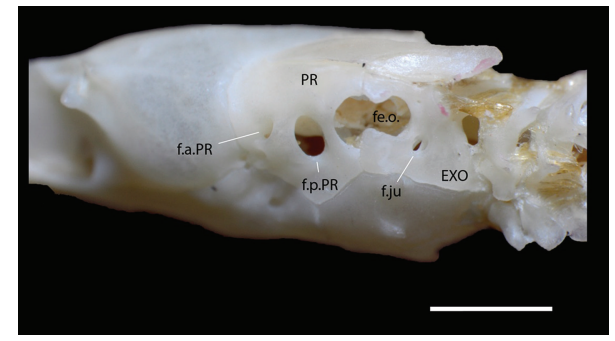

Figure 9: Lateral view of the posterior part of the skull of Sordellina punctata (IBSP 49404). Bar $=2 \mathrm{~mm}$. Abbreviations other than in previous figures: f.a.PR: anterior foramen of prootic; f.ju: jugular foramen; f.p.PR: posterior foramen of prootic; fe.o: fenestra ovalis.

\subsection{Braincase}

4.2.1. Frontal (Figures 3 and 5). A frontal is a paired bone positioned between the nasals and parietal, contributing to the formation of the anterodorsal portion of dermatocranium. The frontal forms the dorsal border and the inner wall of the eye socket. The dorsal surface is smooth, rectangular, with a medial suture between the bones; anterolateral edges are oblique with a process contacting prefrontals, anteromedial region forming a small "V" shaped cavity. Posterodorsal edge is slightly rounded contacting parietal, posterolateral region with a series of three to five foramina; the last foramen is positioned at the suture between the frontal and parietal or at the anterolateral end of parietal. The ventrolateral edge is oblique, forming the inner wall of orbital cavity. Ventrally, frontal is sutured to the anterior portion of parabasisphenoid.

4.2.2. Prefrontal (Figures 3 and 5). The prefrontal is a paired bone, with the lateral face with irregular shape, slightly convex and showing a dorsal process contacting frontal and a ventral process reaching the palatine process of maxilla. In anterior view, prefrontal is dorsoventrally oblique, with a dorsal edge slightly convex and ventral edge concave, with a large lacrimal foramen. In posterior view, there is a small foramen dorsal to the lacrimal foramen. The posterior part of lateral face is slightly concave, forming the anterior edge of the orbital cavity.

4.2.3. Parietal (Figures 3 and 5). It is the largest bone of braincase, being slightly longer in length than wide with triangular shape and smooth surface in dorsal view. Along with the frontals, it forms the roof of the dermatocranium. The anterior edge is concave, contacting frontals; the anterolateral process has a foramen positioned next to the contact with frontal and postorbital. A descending or ventrolateral process of the parietal contacts the medial portion of parasphenoid process. Posteriorly, parietal reaches the supraoccipital and posterolaterally, the prootic. Lateral edges of parietal with two oblique crests that are not confluent in the midline and extend from the postorbital to the level of supraoccipital. Rear edge of parietal rounded.

4.2.4. Postorbital (Figure 3). It is a paired bone, small, sickleshaped, delimits the orbital cavity posteriorly. The posterior face is curved, smooth, and lateroventrally directed. Postorbital does not contact frontal and is connected to the parietal by the anterolateral processes of parietal.

4.2.5. Supraoccipital (Figure 3). It constitutes the part of the roof of the braincase, contacts parietal anteriorly, prootic laterally, and exoccipital posteriorly. It has a medial constriction and the region of contact with parietal is concave. The seams of the posterior portion of the braincase (i.e., between the supraoccipital and the exoccipitals, and between the exoccipitals) form well-defined crests between the boundaries of the bones.

4.2.6. Exoccipital (Figures 3 and 9). It is a paired bone with irregular shape, constitutes the dorsolateral walls of the rear end of the braincase, and it forms the dorsolateral edge of the foramen magnum. Anterodorsally, it contacts the supraoccipital, laterally the prootic, and ventrally the basioccipital. Lateral portion with two large foramina, the fenestra ovalis, which is the boundary between exoccipital and prootic, where the basal plate of columella auris is inserted, and the jugular foramen just below the fenestra ovalis. The jugular foramen allows the passage of the vagus nerve, the glossopharyngeal nerve, the anterior root of the hypoglossal nerve, and the internal jugular vein. The ventral end of exoccipital forms the lateral region of occipital condyle.

4.2.7. Prootic (Figures 5 and 9). It is a paired bone, constitutes part of the posterolateral wall of the braincase. Dorsally and anterolaterally, it contacts the parietal; ventrally, the basisphenoid and basioccipital; dorsoposterioly, the supraoccipital; and posterolaterally, the exoccipital. Supratemporal rests on the dorsoposterior surface connected by fibrous tissue. Laterally, prootic is pierced by two large foramina separated from each other by the laterosphenoid. The anterior and smaller foramen gives passage to the maxilar branch of the trigeminal nerve, while the posterior foramen allows the passage of the mandibular branch of the trigeminal nerve. Two smaller foramina are placed just below the laterosphenoid, and another foramen, slightly larger, can be found laterally, next to the suture with parietal. Posterior edge of prootic contacts the exoccipital, constituting the anterior edge of the fenestra ovalis.

4.2.8. Columella auris (Figure 5). It is a paired bone, consisting of a small discoid plate inserted in the fenestra ovalis that is formed by the prootic and exoccipital. From this basal plate, a narrow bony bar crosses the fenestra ovalis towards a small and elongated process at the medial portion of quadrate.

4.2.9. Basioccipital (Figures 4 and 10). This bone lays medioventrally on the posterior portion of braincase, has a hexagonal shape and forms part of the floor of braincase. It contacts the parabasisphenoid complex anteriorly, the prootic anterolaterally, and the exoccipital posterolaterally. Posteriorly, basioccipital contacts the atlas and constitutes 


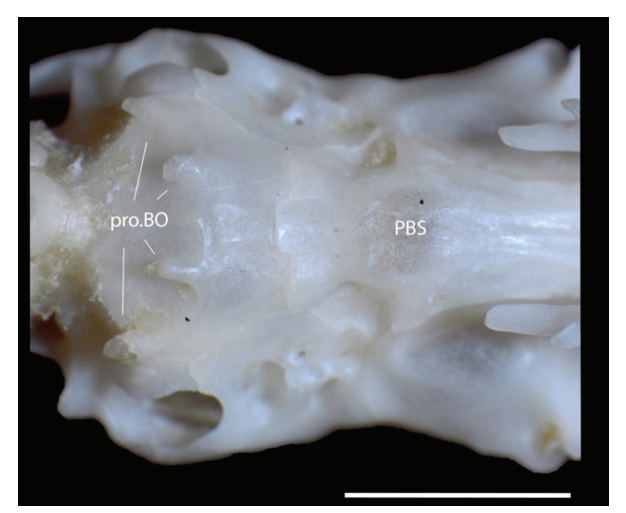

Figure 10: Posteroventral view of the skull of Sordellina punctata (IBSP46054). Bar $=3 \mathrm{~mm}$. Abbreviations other than in previous figures are pro.BO: dentigerous processes of basioccipital.

the ventral edge of foramen magnum. There is a posterior portion with four dentigerous processes, two of them lying posterolaterally, next to the contact with exoccipital, and two medially positioned.

4.2.10. Parabasisphenoid Complex (Figures 4, 5, and 10). It is positioned medioventrally and composed by the parasphenoid and basisphenoid, the latter being anteriorly fused and without visible suture. Along with basioccipital, parabasisphenoid constitutes the floor of braincase. The complex has a spear shape, with the posterior portion (basisphenoid region) broader and the anterior portion (parasphenoid region) becoming narrower approximately on the level of the anterior portion of the pterygoid. The narrowest portion is the anterior end of parasphenoid. Parabasisphenoid contacts parietal and prootic laterally, frontal anteriorly, the dorsal process of the palatine anterolaterally, and the basioccipital posteriorly. Posterolaterally, next to the prootic and basioccipital sutures, a foramen is found on each side, corresponding to the posterior opening to the Vidian canal.

\subsection{Palatomaxillary Apparatus}

4.3.1. Maxilla (Figures 3, 4, 5, 7, 11, and 12). Positioned at the marginal region of the skull, each maxilla is curved anteriorly forming the lateral edge of the anterior portion of the skull. It has approximately half of the length of the braincase and extends approximately from the level of vomer to reach the ectopterygoid, beyond the level of postorbital. There is a medial face with two processes: palatine process, with trapezoidal shape and lying at the anterior third of maxilla, and a rectangular ectopterygoid process positioned at the posterior end. Palatine process of maxilla contacts the ventral side of prefrontal and its medial edge contacts the palatine. Ectopterygoid process of the maxilla articulates with the anterior portion of ectopterygoid. The maxilla delimits the ventral edge of orbital cavity and has 11 to 14 prediastemal teeth (Table 2) and two large, ungrooved, postdiastemal teeth positioned at the ectopterygoid process. Diastema has approximately the size of one dental alveolus.

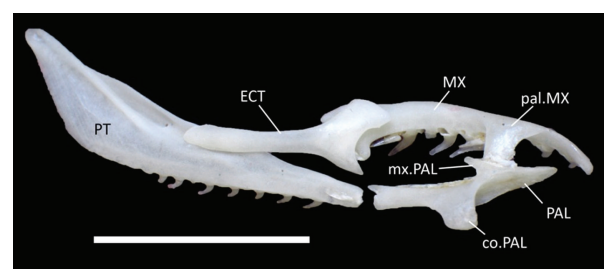

FIGURE 11: Dorsal view of the palatomaxillary complex of Sordellina punctata (IBSP 49404). Bar $=5 \mathrm{~mm}$. Abbreviations other than in previous figures are co.PAL: choanal process of palatine; mx.PAL: maxilar process of palatine; pal. MX: palatine process of maxilla.

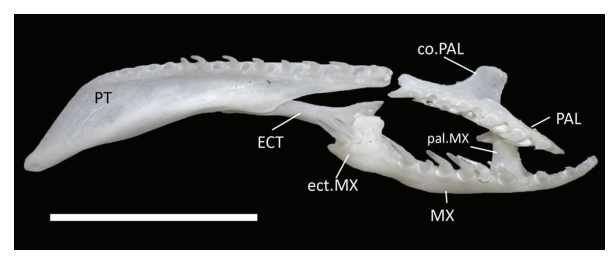

FIgure 12: Ventral view of the palatomaxillary complex of Sordellina punctata (IBSP 49404). Bar $=5 \mathrm{~mm}$. Abbreviations other than in previous figures are ect.MX: ectopterygoid process of maxilla.

Teeth are recurved to the posterior direction and are smaller at the anterior portion.

4.3.2. Palatine (Figures 4, 11, and 12). It is a paired bone with an elongated shape and length shorter than the maxilla. The ventrolateral surface has a process that contacts the palatine process of the maxilla. Approximately at the medial portion, the palatine has a developed, curved, and medially directed dorsal process that contacts the anterior portion of parabasisphenoid process (also called choanal process of palatine). Ventral surface has a longitudinal series of 8 to 11 teeth distributed through the entire length of the palatine (Table 2). The palatine contacts the vomer anterodorsally and pterygoid posteriorly, with the posterolateral branch longer than the posteromedial one.

4.3.3. Pterygoid (Figures 4, 5, 11, and 12). It is a paired bone, elongated, tapered anteriorly, with length of approximately two thirds of the braincase. It contacts the palatine anteriorly, being an extension of the latter and, from there on, the two pterygoid bones converge into a medial direction getting closer at the level of the rear end of teeth rows, diverging laterally in the posterior portion. At the anteroposterior direction, pterygoid becomes broader at the level of the rear end of teeth rows and then becomes tapered posteriorly. The lateral face has a longitudinal crest from the point of contact with ectopterygoid to the posterior portion of pterygoid, which contacts dorsolaterally the outer edge of the trochlear region of the quadrate. Ventral surface exhibits a longitudinal series of 16 to 24 posteriorly directed teeth, positioned on the same line of palatine teeth (Table 2).

4.3.4. Ectopterygoid (Figures 4, 11 and 12). It is a paired bone, elongated, with a length of less than one-third of the 


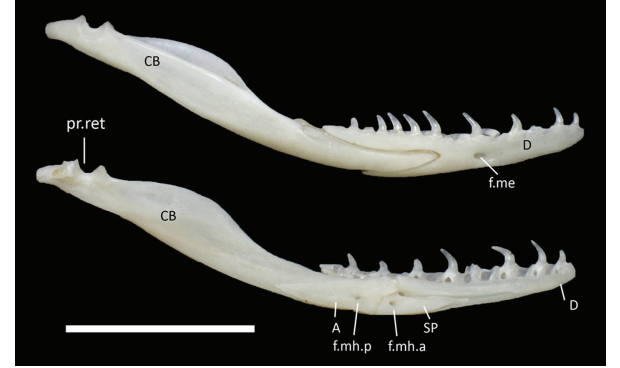

FIgURE 13: Mandible of Sordellina punctata (IBSP 22313). (a) Lateral and (b) medial view. Bar $=5 \mathrm{~mm}$. Abbreviations other than in previous figures are a: angular; f.me: mentonian foramen; f.mh.a: anterior mylohyoid foramen; f.mh.p: posterior mylohyoid foramen pr.ret.: retroarticular process; sp: splenial.

braincase. This bone connects the rear end of maxilla to the median portion of pterygoid. The anterior portion is forked, broad, and flattened, contacting ventrally the ectopterygoid process of the maxilla. The posterior portion is straight and narrow, contacting pterygoid laterodorsally.

\subsection{Suspensorium and Mandible}

4.4.1. Supratemporal (Figures 3 and 5). It is a paired bone, placed at the posterolateral portion of the braincase with an elongated and laminar shape. The anterior edge reaches the dorsal surface of prootic without touching parietal. The posterior edge contacts the lateral side of exoccipital and articulates with dorsal portion of the quadrate. Approximately one-fourth of the bone protrudes the braincase in posterior direction.

4.4.2. Quadrate (Figures 3, 4, and 5). It is a paired bone with a triangular shape in lateral view. The dorsal portion is flat and dilated with a small cephalic condyle articulating with supratemporal. The ventral portion contacts the glenoid cavity of the retroarticular process, forming the quadratearticular joint. The ventromedial portion reaches the posterior portion of pterygoid. The lateral face is relatively flat dorsally, tapering into ventral direction. The medial face is straight in the region of contact with supratemporal and with a small and elongated ventromedial process that connects to the posterior end of columella auris.

4.4.3. Dentary (Figures 5 and 13). It is a paired bone, positioned at the anterior portion of mandible. The anterior end is slightly curved to the opposite hemimandible. The dorsal edge has 14 to 18 conical, approximately subequal in size, and posteriorly oriented teeth (Table 2), extending up to approximately the first quarter of the compound bone. Each tooth has a small vascular nerve foramen in the bottom, corresponding to nutritive foramina for tooth replacement. The dentary is forked posteriorly, with a dorsal process longer than the ventral process. The anterior portion of compound bone is lying between these processes and reaching the level of the ninth to eleventh tooth. The lateral face is convex and pierced by the mentonian foramen. The medial face has a prominent dorsal process limited posteriorly by the angular and ventrally by the splenial (this process is shorter compared to the dorsal process in lateral view, ending before the level of the last four dentary teeth). The ventral process of medial face lies ventrally to the anterior end of splenial.

4.4.4. Splenial (Figure 13). It is a paired bone, small, placed at medial face of mandible, and with spiky shape, the narrowest end pointed to the anterior portion of the mandible. It contacts the angular posteriorly, where the splenial is pierced by the anterior mylohyoid foramen and reaches the dentary anteriorly. Meckel's canal passes above splenial towards the symphyseal process of the dentary.

4.4.5. Angular (Figure 13). It is a paired bone, positioned at medial side of mandible, with triangular and spiky shape, the narrowest end pointed posteriorly. It contacts the medial dorsal process of dentary anterodorsally, where angular is pierced by the posterior mylohyoid foramen and touches the splenial anteroventrally.

4.4.6. Compound Bone (Coronoid + Surangular + Articular) (Figures 5 and 13). It is a paired bone with irregular shape. Corresponds to the biggest bone of mandible and is positioned at the posterior half of the mandible. The posterior end has the retroarticular process and a depression, the glenoid cavity, which articulates with the quadrate. Anteriorly to the glenoid cavity, the inner and outer walls of the compound bone form the surangular crest, which becomes narrower towards the anterior portion where it is closed dorsally. Medial portion of compound bone has a developed prearticular crest. Anterior portion has a dorsal and a ventral process limited by the dentary on the lateral face and by the angular on the medial face.

\section{Distribution}

Sordellina punctata occurs from the Municipality of Ubatuba, state of São Paulo, northern limit of distribution to the Municipality of Criciuma, state of Santa Catarina, southern limit of distribution (Figure 14). The western limit is the Municipality of Piraju, state of São Paulo, Brazil. One specimen (IBSP 10464) is from the Municipality of Porto Esperança, State of Mato Grosso do Sul, Brazil, but this is probably a wrong locality due to a labeling error [2]. The taxon occurs in the Atlantic Forest domain of Brazil, from the sea level up to elevations of 960 meters in the Municipality of Piraquara, state of Paraná, Brazil [18].

\section{Discussion}

The hemipenis of Sordellina punctata was originally described by Zaher [6] and the data presented herein corroborate the previous author. The organ shows no conspicuous calyces and, as pointed out by Zaher [6], the several rows of papillae form a nonconspicuous "capitulum", the papillae 


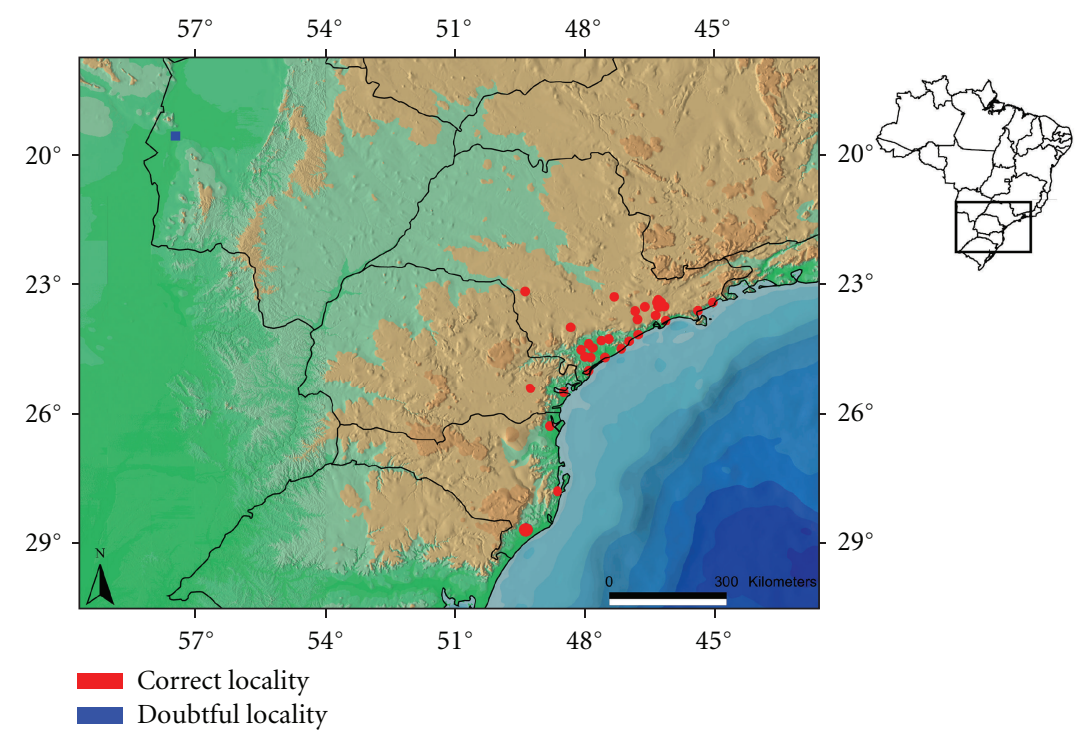

FIGURE 14: Distribution of Sordellina punctata.

being interpreted as vestiges of calyces. Considering data from the literature $[6,19]$ and the phylogenetic hypothesis of Grazziotin et al. [9], we compared the hemipenis of $S$. punctata with representatives of the tribe Echinanterini. The hemipenis of Taeniophallus differs from S. punctata by being generally unilobed and unicalyculate (versus slightly bilobed and with no conspicuous calyces in Sordellina); by being noncapitate or unicapitate (versus semicapitate); asulcate side with a nude interspinal area reaching the apical portion of the organ, except T. brevirostris and T. nicagus that have no interspinal area $[6,19]$ (versus no interspinal area in $S$. punctata). The similarities of the hemipenis of both genera include a divided sulcus spermaticus (except T. nicagus that has a single sulcus), which is a feature shared by most xenodontines and dipsadines [19], branches bifurcating at the base of the capitulum (or the papillate region in $S$. punctata), and with a centrolineal orientation. The general features of the hemipenis of Taeniophallus described above are also found in representatives of Echinantera $[6,19]$, the other genus of the tribe Echinanterini, except that all representatives of Echinantera have noncapitate hemipenis [6].

Considering studies focusing on skull data for Colubridae sensu lato, there are available information for nearly 500 species, representing just a third of the known species and, besides, detailed information is available for an even much smaller number of taxa [17]. According to the phylogenetic hypothesis of Grazziotin et al. [9] and data from the literature, we tried to compare the skull of $S$. punctata with representatives of the tribe Echinanterini but unfortunately the only record is the maxilla of T. nebularis [19], reinforcing the necessity of descriptive studies like this. The skull of $S$. punctata was also compared to members of the tribes Hydropsini (Albuquerque [20], Nunes [21]) and Pseudoboini, such as Clelia (Marques and Lema [22]). These taxa were chosen based on the topology of Grazziottin et al. [9] and available data in the literature.
The ascending process of the premaxilla of Sordellina punctata is similar to members of Clelia, where the process contacts the anterior edge of the nasals. In Clelia, there is a nasal process that stays at the posterior wall of the ascending process [22]. The end of the ascending process of S. punctata is rounded, different from Helicops, with an extremely tapered end, and Hydrops, with a straight end [21]. Vomerine processes of $S$. punctata are elongated and parallel with "U" shaped. Clelia has elongated and convergent vomerine processes, "V" shaped [22]. Helicops has both elongated and short vomerine process among the different species, and Hydrops has an elongated vomerine process [21]. The frontoparietal suture of $S$. punctata is slightly curved posteriorly, while Clelia clelia shows a barely straight suture [22]. Hydrops and some species of Helicops have a strongly curved suture [21].

Parietal crests of $S$. punctata are not in contact in the rear end of the bone, in contrast to some members of Hydropsini and Clelia [21, 22]. Furthermore, parietal extends through almost the proximal third of supraoccipital in S. punctata, as well as in Clelia and some species of Hydropsini. Crests in supraoccipital may extend through all the median portion of the bone, such as in species of Helicops and Hydrops, or supraoccipital may show two posterolateral crests with a third crest situated between them, such as in S. punctata, Clelia, and some species of Helicops [21, 22]. Sordellina punctata, Clelia, and members of Hydropsini have no postorbital processes. Sordellina punctata has a curved maxilla with posteriorly oriented teeth and a diastema separating the prediastemal from the two posterior, enlarged, and ungrooved teeth, as well as Taeniophallus nebularis [19]. Furthermore, the posterior fang is offset laterally in both taxa. Nevertheless, T. nebularis has the maxilla, in lateral view, slightly curved dorsally in the posterior portion, while $S$. punctata has a nearly straight maxilla in lateral view. The largest prediastemal teeth are located in the posterior portion of the maxilla of $S$. punctata, while in 
T. nebularis the largest prediastemal teeth are along the median portion of the maxilla, and the postdiastemal teeth of S. punctata differs from Clelia that have grooved postdiastemal teeth, characteristic of opisthoglyphous snakes $[19,22]$. The presence of diastema occurs in all species of Helicops, Hydrops, and Clelia $[21,22]$. A relevant point that must be mentioned is that the palatomaxillary apparatus of snakes has a diversity of shapes being related to prey selection and feed mechanism [17].

The pterygoid of S. punctata is elongated, articulates with quadrate, has a lateral expansion on the posterior portion, and has a row of teeth, similar to members of Clelia. The pterygoid bones can converge into a medial direction getting closer at the level of the rear end of teeth rows, like in $S$. punctata and some species of Helicops, or they can converge into a medial direction only after the rear end of teeth rows, as in Clelia $[21,22]$.

The ectopterygoid is highly variable, even between supposedly related species [17]. Sordellina punctata has the anterior portion enlarged and slightly bifurcated, overlapping the ectopterygoid process of maxilla and attaching to the medial portion of pterygoid. These characteristics occur in Clelia and some species of Helicops [21, 22]. Supratemporal extends beyond the braincase in $S$. punctata, is slightly curved, and has no contact with parietal anteriorly. The same condition is found in Hydrops, as opposed to some species of Helicops, and Clelia where supratemporal reaches the parietal $[21,22]$. The dentary of Sordellina punctata has a trait common to most colubrids, a medially directed curvature at the anterior portion of the mandible. Besides, the posterior portion has a dorsal and a ventral process [17]. The conspicuously curved posterior teeth of some species of Helicops, differing from S. punctata and other related taxa, is a feature related to piscivory [23].

The use of osteological characters is an important source to investigate the phylogeny of colubrids and other reptile groups [24]. Bones such as frontal and parietal generally bear significant phylogenetic signal, while others are considered to be affected by pressures of prey selection, being generally related to feeding mechanisms, such as the bones of the palatomaxillary arch [17]. The present study shows that $S$. punctata shares some osteological features with taxa of the tribes Pseudoboini and Hydropsini, but detailed descriptions of the skull of representatives of the tribe Echinanteirini and other related taxa are fundamentally important to evaluate the recently proposed hypothesis [9] of phylogenetic relationship among these taxa and $S$. punctata.

\section{Material Examined}

The following specimens were used on the external and internal characteristics. The material was provided by Instituto Butantan (IBSP). [s] skull, [h] hemipenis.

Sordellina punctata: Brazil: Mato Grosso do Sul: Porto Esperança: IBSP 10464; Santa Catarina: Joinville: IBSP 69512; São Paulo: Bertioga: IBSP 68759; Cananéia: IBSP 55332; Capão Bonito: IBSP 46054[s]; Caraguatatuba: IBSP 76782; Eldorado Paulista: IBSP 56081[h]; Embu: IBSP 42518, 62203, 62809[s,h], 71106[s,h], 72874[h]; Embu-Guaçu: IBSP
54552; Iguape: IBSP 40166, 40851, 41186[s], 49404[s], 56066, 56068, 72371; Itanhém: IBSP 66199; Jacurupinga: IBSP 24313, 74454; Juquiá: IBSP 22313[s]; Miracatu: IBSP 32762, 46023, 46611; Mogi das Cruzes: IBSP 9077; PariqueraAçu: IBSP 32749[s], 40285, 48744[s], 73908; Peruíbe: IBSP 57875; Piraju: IBSP 67661, 67696, 67818; Poá: IBSP 25130, 41375, 41377, 41408; Registro: IBSP 41071[s], 52934; Rio Grande da Serra: IBSP 46958, 46959, 55692, 55693[h]; São Paulo: IBSP 6791, 22936, 22937, 33201, 34286, 34290, 42914, 49190, 57742; Sete Barras: IBSP 33696, 74951; Suzano: IBSP 55084; Ubatuba: IBSP 69511; Paraná: Curitiba: IBSP 40760; Paranaguá: IBSP 20481.

\section{Acknowledgments}

The authors would like to thank F. L. Franco for access to the specimens from Instituto Butantan. They thank J. P. Pombal Jr. for allowing the use of the stereomicroscope with digital camera located in the Setor de Herpetologia, Departamento de Vertebrados, Museu Nacional/UFRJ. They also would like to thank the reviewers for the suggestions and contributions on this paper. B. H. V. Miranda was supported by Coordenação de Aperfeiçoamento de Pessoal de Nível Superior (CAPES) and D. S. Fernandes was supported by Conselho Nacional de Desenvolvimento Científico e Tecnológico $(\mathrm{CNPq})$ and by Fundação de Amparo à Pesquisa do Estado do Rio de Janeiro (FAPERJ).

\section{References}

[1] O. A. V. Marques, A. Eterovic, and I. Sazima, Serpentes da Mata Atlântica-Guia Ilustrado para a Serra do Mar, Holos, Ribeirão Preto, Brazil.

[2] D. N. Pereira, F. Stender-Oliveira, M. G. Rodrigues, and R. S. Bérnils, "Distribution and habitat use of Sordellina punctata (Serpentes, Colubridae), with a new record from State of São Paulo, Brazil," Herpetological Bulletin, no. 100, pp. 18-22, 2007.

[3] A. R. Hoge, "Die systematische stellung von Xenodon punctatus Peters 1880 und Philodryas taeniatus Hensel 1868," Mitteilungen aus dem Zoologischen Museum in Berlin, vol. 34, pp. 49-56, 1958.

[4] J. A. Peters and B. Orejas-Miranda, "Catalogue of the neotropical squamata-part I. Snakes," Bulletin of the United States Natural Museum, vol. 297, pp. 1-347, 1970.

[5] A. R. Hoge and S. A. R. W. D. L. Romano, "Redescription and range of Sordellina punctata (Peters) (Serpentes: Colubridae)," Memórias do Instituto Butantan, vol. 40-41, pp. 63-70, 1978.

[6] H. Zaher, "Hemipenial morphology of the South American xenodontine snakes, with a proposal for a monophyletic Xenodontinae and a reappraisal of colubroid hemipenes," Bulletin of the American Museum of Natural History, no. 240, pp. 1-168, 1999.

[7] H. Zaher, F. G. Grazziotin, J. E. Cadle, R. W. Murphy, J. C. de Moura-Leite, and S. L. Bonatto, "Molecular phylogeny of advanced snakes (Serpentes, Caenophidia) with an emphasis on South American xenodontines: a revised classification and descriptions of new taxa," Papéis Avulsos de Zoologia, vol. 49, no. 11, pp. 115-153, 2009.

[8] N. Vidal, M. Dewynter, and D. J. Gower, "Dissecting the major American snake radiation: a molecular phylogeny of 
the Dipsadidae Bonaparte (Serpentes, Caenophidia)," Comptes Rendus Biologies, vol. 333, no. 1, pp. 48-55, 2010.

[9] F. G. Grazziotin, H. Zaher, and R. W. Murphy, "Molecular phylogeny of the New World Dipsadidae (Serpentes: Colubroidea): a reappraisal," Cladistics, no. 1, pp. 1-23, 2012.

[10] J. A. Peters, Dictionary of Herpetology-A Brief and Meaningful Definition of Words and Terms Used in Herpetology, Hafner Publishing Company, New York, NY, USA, 1964.

[11] H. G. Dowling, "A proposed standard system of counting ventrals in snakes," British Journal of Herpetology, vol. 1, pp. 97-99, 1951.

[12] J. H. Zar, Biostatistical Analysis, Prentice-Hall, 4th edition, 1999.

[13] O. S. Pesantes, "A method for preparing the hemipenis of preserved snakes," Journal of Herpetology, vol. 28, no. 1, pp. 93-95, 1994.

[14] H. G. Dowling and J. M. Savage, "A guide to the snake hemipenis: a survey of basic structure and systematic characteristics," Zoologica, vol. 45, pp. 17-28, 1960.

[15] G. Hangay and M. Dingley, Biological Museum Methods, Academic Press, 1985.

[16] G. L. Underwood, "A contribution to the classification of snakes," British Museum of Natural History, vol. 653, pp. 1179, 1967.

[17] D. Cundall and F. J. Irish, "The snake skull," in Biology of the Reptilia, C. Gans, A. S. Gaunt, and K. Adler, Eds., vol. 20, pp. 349-692, Society for the Study of Amphibians and Reptiles, 2008.

[18] R. S. Bérnils, Composição e padrões de distribuição de Caenophidia (Squamata, Serpentes) das serras atlânticas e planaltos do sudeste da América do Sul [Ph.D. thesis], Museu Nacional, Universidade Federal do Rio de Janeiro, Brazil, Rio de Janeiro, Brazil, 2009.

[19] W. E. Schargel, G. Rivas Fuenmayor, and C. W. Myers, "An enigmatic new snake from cloud forest of the Península de Paria, Venezuela (Colubridae: Genus Taeniophallus?)," American Museum Novitates, no. 3484, pp. 1-22, 2005.

[20] N. R. Albuquerque, "Osteologia craniana, morfologia do hemipênis e o posicionamento sistemático do gênero Hydrops Wagler, 1830 (Serpentes: Colubridae)," Comunicações do Museu de Ciências e Tecnologia da PUCRS, série Zoológica, vol. 15, no. 1, pp. 41-54, 2002.

[21] P. M. S. Nunes, Filogenia da tribo Hydropsini baseada em caracteres morfológicos (Serpentes: Xenodontinae) [MSc. dissertation], Universidade de São Paulo, São Paulo, Brazil, 2006.

[22] L. B. Marques and T. Lema, "Estudo comparativo da osteologia craniana de Clelia occipitolutea (Duméril, Bibron et Duméril, 1854) e C. rustica (Cope, 1878) (Serpentes: Colubridae: Xenodontinae: Pseudoboini)," Acta Biologica Leopoldensia, vol. 14, no. 1, pp. 27-54, 1992.

[23] A. H. Savitzky, "Coadapted character complexes among snakes: fossoriality, piscivory, and durophagy," Integrative and Comparative Biology, vol. 23, no. 2, pp. 397-409, 1983.

[24] O. Rieppel, "Patterns of diversity in the reptilian skull," in The Skull, vol. 2, Patterns of Structural and Systematic Diversity, J. Hanken and B. K. Hall, Eds., pp. 344-390, University of Chicago Press, Chicago, Ill, USA, 1993. 

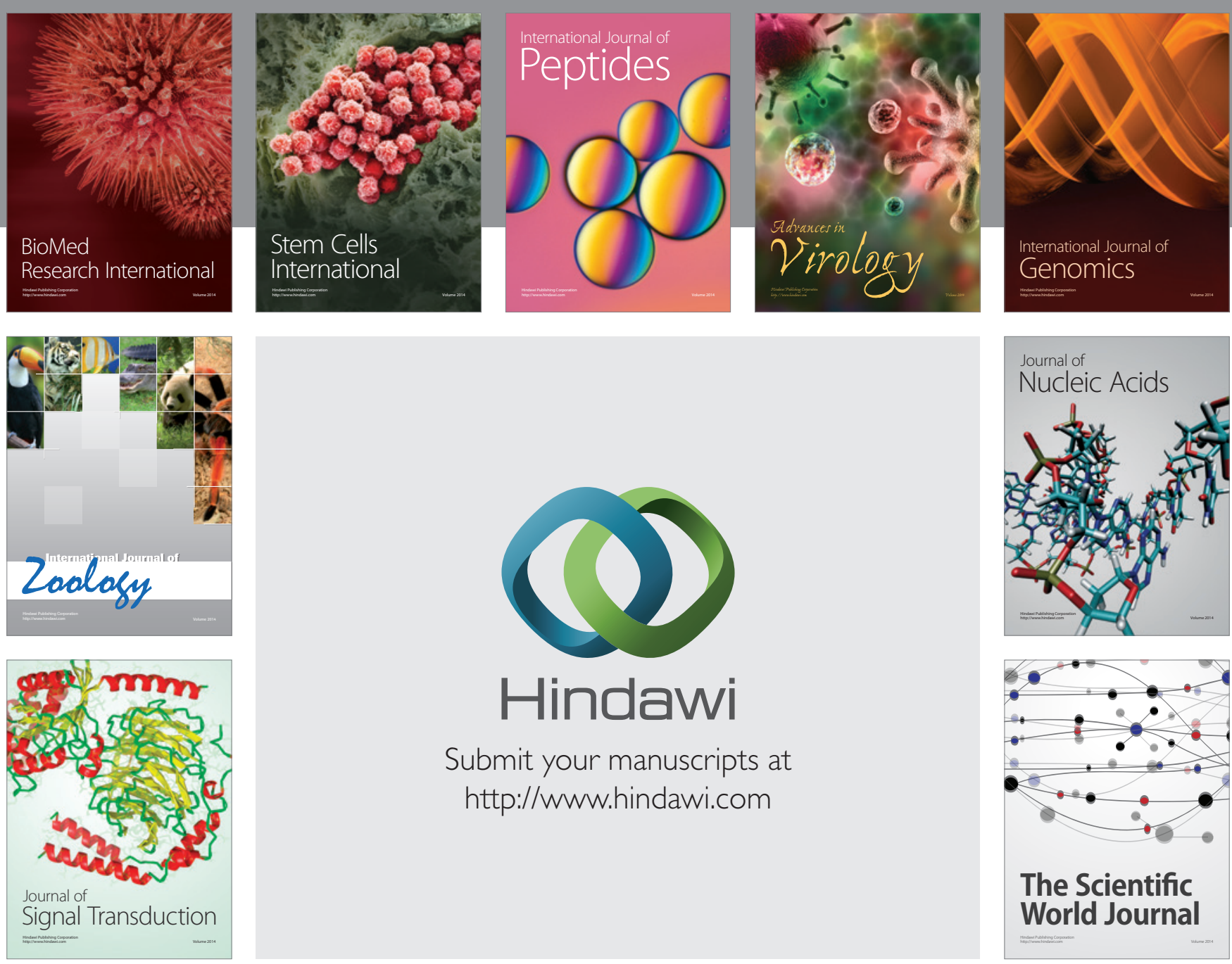

Submit your manuscripts at

http://www.hindawi.com
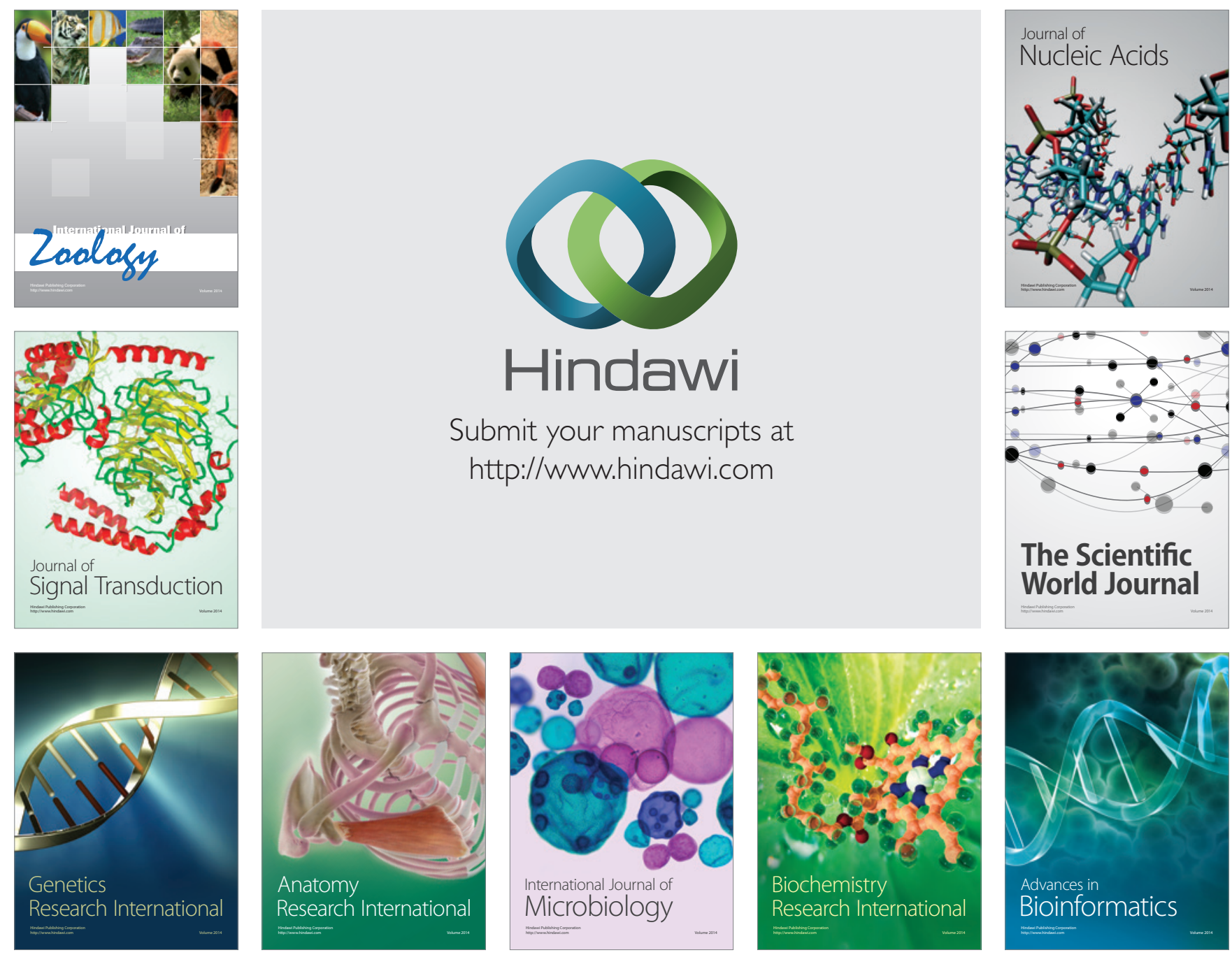

The Scientific World Journal
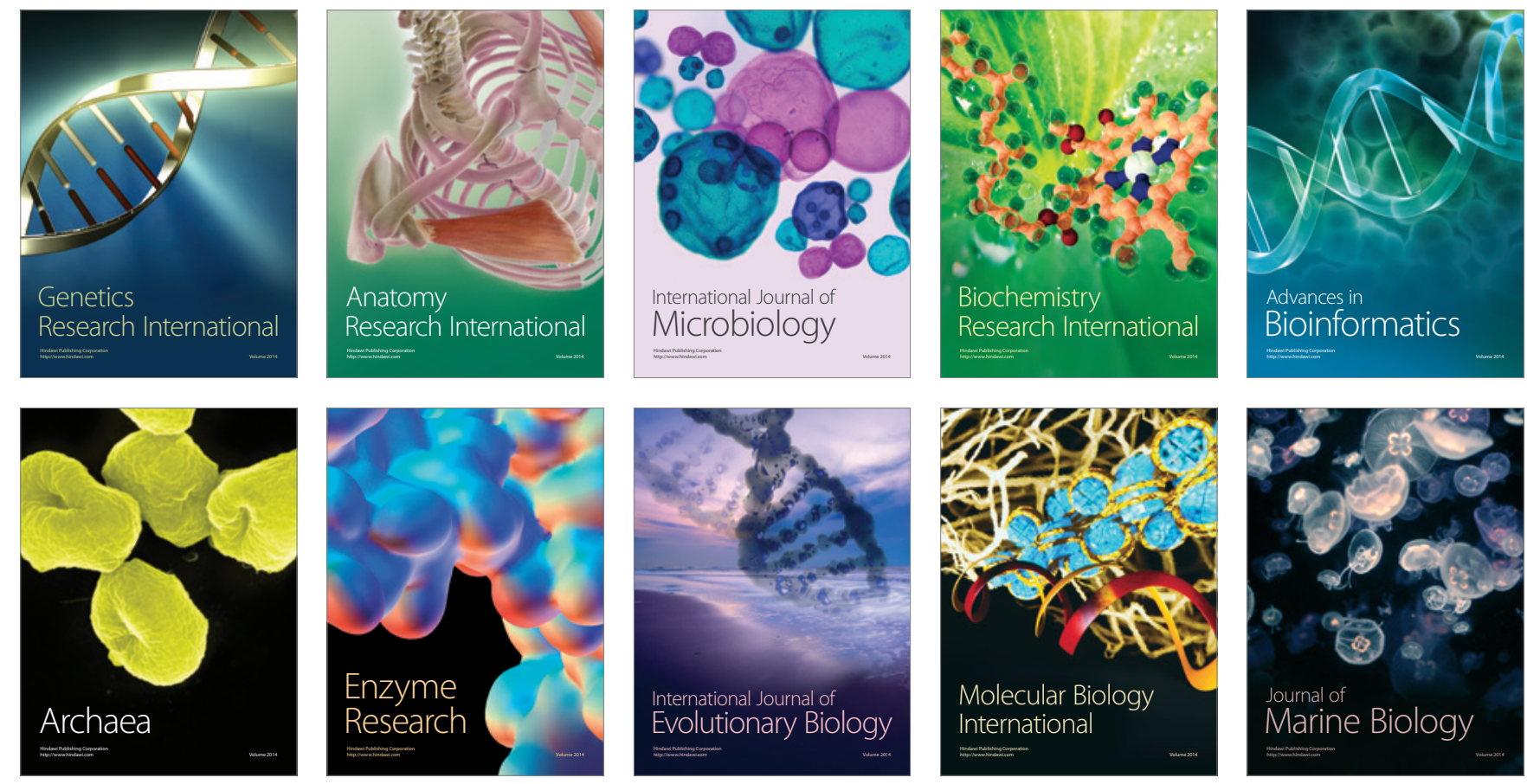